\title{
GESTÃO DE PROCESSO DE COMPARTILHAMENTO DO CONHECIMENTO TECNOLÓGICO EM UMA EMPRESA DO SETOR ELÉTRICO (CEMIG)
}

\author{
MANAGEMENT OF THE PROCESS OF SHARING \\ TECHNOLOGICAL KNOWLEDGE IN NA ELETRIC \\ SECTOR COMPANY (CEMIG)
}

\author{
Marcela Augusta da Silva Gomes Silveira \\ Fabricio Zivianib \\ Marta Araújo Tavares Ferreira ${ }^{c}$ \\ Ricardo Viana Carvalho de Paivad
}

\begin{abstract}
RESUMO
Introdução: A transferência do conhecimento tácito é fator de vantagem competitiva para as organizações. Nesse contexto, esse estudo tem como objetivo analisar a influência dos fatores relevantes à transferência do conhecimento tecnológico em uma organização. Objetivo: Buscou-se a compreensão das teorias e conceitos aplicados ao conhecimento, gestão do conhecimento e à transferência e compartilhamento do conhecimento. Metodologia: Para consecução desse objetivo, aplicou-se um questionário estruturado, com escala likert de 5 pontos. Essa pesquisa, trata-se de uma pesquisa descritiva, quantitativa, que tem como objeto de análise a Companhia Energética de Minas Gerais- CEMIG. Resultados: Como resultado identificou-se que a empresa não possui uma política ou estratégia definida para incentivar a transferência do conhecimento e ainda precisa melhorar a cultura organizacional que incentive sua transmissão. Apesar de não haver restrições quanto aos fatores idiossincráticos e estrutura organizacional. Conclusões: Conclui-se então, que os fatores Tempo, Linguagem, Confiança, Conhecimento Valorizado, Poder, Ambiente Favorável, Rede de Relacionamento, Hierarquia, Mídia, Reconhecimento e Recompensa, Treinamento, Transmissão de Conhecimento, Armazenagem do

\footnotetext{
a Doutor em Ciência da Informação pela Escola de Ciência da Informação da Universidade Federal de Minas Gerais. Professor da Universidade do Estado de Minas Gerais. E-mail: marcela@cemig.com.br

b Doutor em Ciência da Informação pela Escola de Ciência da Informação da Universidade Federal de Minas Gerais (PPGCl-UFMG). E-mail: fazist@hotmail.com

c Doutora em Engenharia Industrial e Gestão da Inovação Tecnológica pela École Centrale des Arts et Manufactures de Paris. E-mail: marta.tavarez@gmail.com

d Doutor em Administração. E-mail: ricardovcp@gmail.com
} 
Conhecimento, Redes Sociais Digitais são influenciadores diretos do Compartilhamento do Conhecimento Tácito.

Descritores: Conhecimento. Gestão do conhecimento. Transferência do conhecimento. Compartilhamento do conhecimento. Setor elétrico.

\section{INTRODUÇÃO}

O desenvolvimento industrial e a entrada dos anos $70 \mathrm{fez}$ com que os modelos de gestão existentes não respondessem aos desafios crescentes que afetavam as organizações. Um novo paradigma surge: a passagem da Sociedade Industrial para a Sociedade do Conhecimento. O conhecimento passa a ser considerado como um recurso de grande valor competitivo, pois promove a inovação, que gera vantagem competitiva para a empresa (DRUCKER, 1993; NONAKA; TAKEUCHI, 1997; LEONARD; SENSIPER, 1998).

Uma economia baseada no conhecimento proporciona instrumentos úteis para gerir o capital humano e preservar o passado (DRUCKER, 2013; URSO et al., 2009). No entanto, Davenport e Prusak (2003) afirmam que a mera existência do conhecimento em alguma parte da organização é de pouca ajuda; o conhecimento só é um ativo corporativo valioso quando está acessível, e seu valor aumenta na proporção do grau de acessibilidade. Por isso, a existência da preocupação com o gerenciamento conhecimento existente nas organizações (HANSEN; NOHRIA; TIERNEY, 1999). As empresas devem ter a capacidade de desenvolver, armazenar, organizar, distribuir e integrar 0 conhecimento adquirido, de modo a que o seu uso favoreça e apoie a tomada de decisões estratégicas e assegure rentabilidade e durabilidade a longo termo (SIMONE; ACKERMAN; WULF, 2012).

Um dos aspectos mais relevantes para o gerenciamento do conhecimento é a sua transferência pela organização. Campos (2008) destaca que a disseminação e transferência do conhecimento tem sido, desde há muito, o principal gargalo no processo de gestão do conhecimento- GC, uma vez que elementos determinantes do conhecimento estão enraizados em pessoas ou 
locais específicos. O grande diferencial de competitividade de uma organização está em sua capacidade de otimizar a reutilização do conhecimento, o qual, muitas vezes, fica restrito a indivíduos ou a algumas áreas; enquanto os demais lutam com problemas que poderão ser solucionados com 0 conhecimento já dominado internamente.

Dada a importância do conhecimento para as organizações e a necessidade de ampliar estudos relativos às ações que impactam a transferência e o compartilhamento de conhecimento nas empresas, foi desenvolvido o presente estudo, que tem como objetivo analisar a influência dos fatores relevantes à transferência do conhecimento tecnológico em uma organização, na CEMIG. Esse estudo também visa responder ao problema: Qual(is) o(s) fator(es) "influentes" ao processo de transferência e compartilhamento do conhecimento tecnológico na CEMIG?

A pesquisa está estruturada em seis seções. A primeira realizou uma breve introdução sobre a pesquisa; a segunda seção traz à luz da teoria, os principais conceitos para compreensão do estudo; a terceira seção apresenta a metodologia e o instrumento de pesquisa utilizados; seguinte, a quarta sessão contempla a apresentação, análise e discussão dos resultados. Por fim, a quinta seção apresenta as considerações finais, seguida das referências bibliográficas utilizadas.

\section{A INTERDEPENDÊNCIA ENTRE A CRIAÇÃO E TRANSFERÊNCIA DO CONHECIMENTO}

A construção de uma sociedade do conhecimento é a melhor maneira para sustentar o modelo de sociedade sem que seja necessário fazer um tradeoff entre crescimento económico, a coesão social e a proteção do ambiente. $O$ conhecimento é resultado da interpretação da informação e de sua utilização para algum fim, especificamente para gerar novas ideias, resolver problemas ou tomar decisões e é conhecimento é construído por um indivíduo que alimenta a construção do conhecimento coletivo (MORAES, 2014). Segundo 
Nonaka (1991) existem duas formas de conhecimento: o tácito e o explícito. O conhecimento tácito está intimamente ligado aos modelos mentais, concepções, e ações de uma pessoa, sendo frequentemente específico a um determinado contexto histórico-social. Por essa razão, o conhecimento tácito é difícil de expressar, codificar e transferir (HALDIN-HERRGARD, 2000).

O conhecimento explícito é aquele de fácil identificação e codificação, sendo geralmente expresso em técnicas, métodos e padrões. Para tratar esses conhecimentos é preciso um modo ou sistema para capturar, analisar, interpretar, organizar, mapear e difundir a informação. (DRUCKER, 2013; O'DELL; GRAYSON, 1998). Murray e Peirefitte (2007) destacam que a criação e a transferência do conhecimento são formas pelas quais os membros de uma organização aprendem e criam novos conhecimentos. A criação e a transferência do conhecimento de forma efetiva pela organização propiciam às empresas maximizar vantagem competitiva proveniente do conhecimento. Nesse caso, foca-se, além do conhecimento transferido, todo o suporte organizacional para que as necessidades de aprendizagem sejam satisfeitas.

$O$ processo de criação e compartilhamento de conhecimento para Nonaka e Takeuchi (1997) caracteriza-se como um processo contínuo, em que o conhecimento flui pela organização, envolvendo indivíduos e tecnologia e, ainda, abrangendo conhecimento tácito e explícito. Mas para que a organização tenha acesso ao conhecimento, é preciso que as pessoas estejam dispostas a cedê-lo e manter contato, sejam internos ou externos (FLEURY; OLIVEIRA JUNIOR, 2001). Para Davenport e Prusak (2003) e Angeloni (2008) deve-se reconhecer que o conhecimento tem origem e reside na cabeça das pessoas e que o compartilhamento do capital intelectual exige conhecimento prévio do conteúdo a ser compartilhado. $O$ uso de uma também tecnologia possibilita novos comportamentos ligados ao conhecimento.

A certeza de que a informação válida pode fluir livremente entre colegas de trabalho ou entre parceiros e a existencia de confiança entre eles, são críticas para uma operação bem sucedida em uma organização. O compartilhamento aberto de conhecimento relevante tem o potencial para 
Marcela Augusta da Silva Gomes Silveira, Marta Araújo Tavares Ferreira, Ricardo Viana Carvalho de Paiva

Gestão de processo de compartilhamento do conhecimento tecnológico em uma empresa do setor elétrico (CEMIG)

reduzir os custos e otimização de processos, ao passo que a falta do compartilhamento pode prejudicar organizações e até mesmo tornar seus processos ineficazes (RUTTEN; BLAAS-FRANKEN; MARTIN, 2016). Nessa perspectiva, o instrumento de pesquisa desse estudo aborda questões para o processo de transferência do conhecimento Tácito no quadro 1.

Quadro 1 - Fatores Transferência do conhecimento tácito

\begin{tabular}{|c|c|c|}
\hline Item & Descrição & Autores \\
\hline D1 & $\begin{array}{l}\text { Fazemos encontros informais (cafés, happy hours, outros) ou formais } \\
\text { (reuniões, jantares, almoços, outros) com a finalidade de compartilhar o } \\
\text { que sabemos com os demais empregados. }\end{array}$ & Moraes (2014) \\
\hline $\mathrm{D} 2$ & $\begin{array}{l}\text { Alternamos as tarefas entre as pessoas para que outros saibam } \\
\text { executar atividades específicas. }\end{array}$ & Moraes (2014) \\
\hline D3 & $\begin{array}{l}\text { A empresa promove encontros e treinamentos junto aos fornecedores e } \\
\text { clientes, com o objetivo de capacitá-los. }\end{array}$ & $\begin{array}{l}\text { Fleury e Oliveira Junior } \\
(2001)\end{array}$ \\
\hline D4 & $\begin{array}{l}\text { A empresa mantém contato com sujeitos externos (clientes, } \\
\text { fornecedores ou outras partes) com o objetivo de repassar informações } \\
\text { de interesse comum. }\end{array}$ & $\begin{array}{l}\text { Fleury e Oliveira Junior } \\
(2001)\end{array}$ \\
\hline D5 & $\begin{array}{l}\text { Ouvimos nossos clientes externos a fim de ter conhecimento sobre } \\
\text { suas reclamações e sugestões. }\end{array}$ & $\begin{array}{l}\text { Rutten, Blaas-Franken e } \\
\text { Martin (2016) }\end{array}$ \\
\hline D6 & $\begin{array}{l}\text { Participamos de reuniões junto aos nossos fornecedores para } \\
\text { alinhamento de objetivos expectativas. }\end{array}$ & $\begin{array}{l}\text { Rutten, Blaas-Franken e } \\
\text { Martin (2016) }\end{array}$ \\
\hline D7 & $\begin{array}{l}\text { Somos orientados a formalizar, por escrito, o que sabemos sobre } \\
\text { nossas atividades. }\end{array}$ & $\begin{array}{l}\text { Drucker (2013); O'dell e } \\
\text { Grayson (1998) }\end{array}$ \\
\hline D8 & $\begin{array}{l}\text { A gerência promove mudanças nos processos internos a fim de } \\
\text { melhorar o compartilhamento dos nossos conhecimentos. }\end{array}$ & $\begin{array}{l}\text { Drucker (2013); O'dell e } \\
\text { Grayson (1998) }\end{array}$ \\
\hline D9 & $\begin{array}{l}\text { A empresa disponibiliza um repositório (intranet, sistema de gestão do } \\
\text { conhecimento, wikis) para que os colaboradores compartilhem seus } \\
\text { conhecimentos. }\end{array}$ & $\begin{array}{l}\text { Nonaka e Takeuchi (1997) } \\
\text { e Angeloni (2008). }\end{array}$ \\
\hline D10 & $\begin{array}{l}\text { Recebo divulgação, por meio impresso ou digital, de informações sobre } \\
\text { políticas e normas internas. }\end{array}$ & Angeloni (2008) \\
\hline D11 & $\begin{array}{l}\text { Orientamos, por meio de blogs, twitter, ou outras mídias, a troca de } \\
\text { experiências e opiniões entre nossos clientes. }\end{array}$ & Angeloni (2008) \\
\hline D12 & $\begin{array}{l}\text { Damos incentivos a nossos clientes para que compartilhem suas } \\
\text { experiências. }\end{array}$ & $\begin{array}{l}\text { Rutten, Blaas-Franken e } \\
\text { Martin (2016) }\end{array}$ \\
\hline D13 & $\begin{array}{l}\text { Ouvimos o que nossos clientes dizem para que possamos melhorar } \\
\text { nossos produtos, processos e sistemas. }\end{array}$ & $\begin{array}{l}\text { Rutten, Blaas-Franken e } \\
\text { Martin (2016) }\end{array}$ \\
\hline D14 & $\begin{array}{l}\text { Analisamos as contribuições de nossos fornecedores quanto aos } \\
\text { processos da empresa. }\end{array}$ & $\begin{array}{l}\text { Fleury e Oliveira Junior } \\
(2001)\end{array}$ \\
\hline D15 & $\begin{array}{l}\text { Somos transparentes quanto à divulgação de informações da empresa } \\
\text { para nossos clientes e fornecedores. }\end{array}$ & $\begin{array}{l}\text { Rutten, Blaas-Franken e } \\
\text { Martin (2016) }\end{array}$ \\
\hline D16 & $\begin{array}{l}\text { Disponibilizamos aos nossos clientes e fornecedores sistemas de } \\
\text { divulgação de notícias, procedimentos e normas internas. }\end{array}$ & $\begin{array}{l}\text { Rutten, Blaas-Franken e } \\
\text { Martin (2016) }\end{array}$ \\
\hline D17 & $\begin{array}{l}\text { Estabelecemos processos para que os membros da organização } \\
\text { orientem-se quanto à realização de suas atividades. }\end{array}$ & $\begin{array}{l}\text { Drucker (2013); O'dell e } \\
\text { Grayson (1998) }\end{array}$ \\
\hline D18 & $\begin{array}{l}\text { Integramos nossos sistemas de informação para que disponibilizem } \\
\text { informações da empresa, produtos e processos relevantes aos nossos } \\
\text { colaboradores. }\end{array}$ & $\begin{array}{l}\text { Nonaka e Takeuchi (1997) } \\
\text { e Angeloni (2008). }\end{array}$ \\
\hline
\end{tabular}

Fonte: Adaptado de Nonaka e Takeuchi (1997); Drucker (2013); O'dell e Grayson (1998); Angeloni (2008); Moraes (2014); Fleury e Oliveira Junior (2001); Rutten, BlaasFranken e Martin (2016).

Inf. Inf., Londrina, v. 23, n. 2, p. 538 - 565, maio/ago. 2018. http://www.uel.br/revistas/informacao/ 
Os itens da pesquisa, quanto aos fatores da transferência do conhecimento tácito contemplam: a utilização de reuniões, sejam formais ou informais para o compartilhamento do conhecimento (MORAES, 2014); alternância de tarefas (MORAES, 2014); encontros com agentes externos, como clientes e fornecedores (FLEURY; OLIVEIRA JUNIOR, 2001; RUTTEN; BLASS-FRANKEN; MARTIN, 2016); orientações de trabalho e formalizações, inclusive de mudanças (O'DELL; GRAYSON, 1998; DRUCKER, 2013); fornecimento e utilização de repositório de dados e mídias sociais por parte dos colaboradores internos (ANGELONI, 2008) e externos (RUTTEN, BLASSFRANKEN; MARTIN, 2016); sistemas de informação (NONATA; TAKEUCHI, 1997; ANGELONI, 2008), entre outros itens considerados relevantes para a pesquisa.

\subsection{Fatores influenciadores à transferência do conhecimento tácito}

O conhecimento tácito não pode ser ensinado, deve ser aprendido. Por isso, a disseminação desse conhecimento pela organização é mais complexa (HALDIN-HERRGARD, 2000). Diversos fatores organizacionais podem ser benéficos ou inibidores para a transferência do conhecimento tácito, como: cultura organizacional, fatores idiossincráticos, estrutura organizacional, estratégia de gestão do conhecimento, redes digitais, entre outros.

Os fatores idiossincráticos (QUADRO 2) são representados por: i) tempo, haja vista que a transferência do conhecimento requer tempo para que se possa viver a experiência, refletir sobre ela e proporcionar interações pessoais (SZULANSKI, 1996; LEONARD; SENSIPER, 1998; ii) linguagem, para não haver falhas de comunicação (HALDIN-HERRGARD, 2000; DAVENPORT; PRUSAK, 2003;) e; iii) confiança, para que as pessoas tenham menor resistência em fornecer e absorver o conhecimento útil (DISTERER, 2003). 
Quadro 2 - Fatores Idiossincráticos: tempo, linguagem e comunicação

\begin{tabular}{|c|c|c|}
\hline Item & Descrição & Autores \\
\hline 11 & $\begin{array}{l}\text { Eu tenho tempo e oportunidade para compartilhar com e receber } \\
\text { conhecimento de outras pessoas. A empresa incentiva que eu tenha } \\
\text { tempo para compartilhar o conhecimento que possuo com outras } \\
\text { pessoas. }\end{array}$ & $\begin{array}{l}\text { Leonard e Sensiper (1998) } \\
\text { Roberts (2000) }\end{array}$ \\
\hline 13 & $\begin{array}{l}\text { Tenho facilidade de compartilhar verbalmente o conhecimento que } \\
\text { possuo. }\end{array}$ & $\begin{array}{l}\text { Haldin-Herrgard }(2000) \\
\text { Davenport e Prusak }(2003)\end{array}$ \\
\hline 14 & Conheço e entendo todas as terminologias usadas na empresa & $\begin{array}{l}\text { Haldin-Herrgard }(2000) \\
\text { Davenport e Prusak (2003) }\end{array}$ \\
\hline 15 & $\begin{array}{l}\text { Sinto-me seguro ao compartilhar informações e conhecimento com } \\
\text { meus colegas. }\end{array}$ & Dister (2003) \\
\hline 16 & $\begin{array}{l}\text { Só compartilho meu conhecimento com colegas que também } \\
\text { compartilham seu conhecimento comigo. }\end{array}$ & Dister (2003) \\
\hline
\end{tabular}

Fonte: Adaptado de Leonard e Sensiper (1998); Haldin-Herrgard (2000); Roberts (2000); Dister (2003); Davenport e Prusak (2003).

Conforme quadro 2, os itens utilizados para verificação dos fatores idiossincráticos foram: o tempo disponibilizado pelo colaborador e pela organização para o compartilhamento de informações (LEONARD; SENSIPER, 1998; ROBERTS, 2000); as habilidades de compartilhamento de conhecimento (HALDIN-HERRGARD, 2000; DAVENPORT; PRUSAK, 2003), bem como a segurança que se tem em realizar esse processo (DISTER, 20003); e o conhecimento das tecnologias utilizadas pela empresa que podem apoiar a transferência do conhecimento (HALDIN-HERRGARD, 2000; DAVENPORT; PRUSAK, 2003).

A estrutura organizacional compõe fatores relacionados à: i) mídia, que permiti o compartilhamento de visões, insights, rápido entendimento e utilização de uma variedade de linguagens comum à todos (DAFT; LENGEL, 1986; DAFT; LENGEL; TREVINO, 1987); ii) hierarquia, para que haja acessibilidade ao conhecimento, independentemente de posição hierárquica (FAHEY; PRUSAK , 2001) e; iii) Redes de Relacionamento, que permita identificar as pessoas que possuem os conhecimentos de que se necessita (DISTERER, 2003; LEMOS, 2008) (QUADRO 3). 
Quadro 3 - Fatores Estrutura organizacional: mídia, hierarquia e redes de relacionamento

\begin{tabular}{|c|c|c|}
\hline Item & Descrição & Autores \\
\hline EO1 & $\begin{array}{l}\text { Eu sei exatamente quem na empresa possui o conhecimento } \\
\text { específico que pode ajudar o meu trabalho. }\end{array}$ & $\begin{array}{l}\text { Daft e Lengel (1986); Daft, } \\
\text { Lengel e Trevino (1987) }\end{array}$ \\
\hline EO2 & $\begin{array}{l}\text { Desconheço quem detém o conhecimento mais profundo de } \\
\text { determinado assunto dentro da empresa. }\end{array}$ & $\begin{array}{l}\text { Daft e Lengel (1986); Daft, } \\
\text { Lengel e Trevino (1987) }\end{array}$ \\
\hline EO3 & $\begin{array}{l}\text { Tenho acesso às pessoas que detém o conhecimento tácito que } \\
\text { necessito, independentemente do nível hierárquico em que se } \\
\text { encontra. }\end{array}$ & Fahey e Prusak (2001) \\
\hline EO4 & $\begin{array}{l}\text { Sinto-me à vontade de pedir ajuda quando a posição de quem detém } \\
\text { o conhecimento é superior a minha }\end{array}$ & Fahey e Prusak (2001) \\
\hline EO5 & $\begin{array}{l}\text { A mídia que mais utilizo para interagir com pessoas na empresa cujo } \\
\text { conhecimento é importante para meu trabalho é a conversa pessoal. }\end{array}$ & Dister (2003); Lemos (2008) \\
\hline EO6 & $\begin{array}{l}\text { A mídia que mais utilizo para interagir com pessoas na empresa, cujo } \\
\text { conhecimento é importante para o meu trabalho é através de e-mail, } \\
\text { telefone, memorandos, relatórios e afins. }\end{array}$ & Dister (2003); Lemos (2008) \\
\hline
\end{tabular}

Fonte: Adaptado de Daft e Lengel (1986), Daft, Lengel e Trevino (1987), Fahey e Prusak (2001), Dister (2003) e Lemos (2008).

O Quadro 3 apresenta os itens de pesquisa relacionados ao fator de Estrutura Organizacional. Os itens contemplam a análise o conhecimento das pessoas que detém informações sobre as atividades; 0 acesso que colaboradores possuem à essas pessoas e à sua gerência direta; além das mídias utilizadas como meio de interação entre colaboradores, entre outros fatores (DAFT; LENGEL, 1986; DAFT; LENGEL; TREVINO, 1987; FAHEY; PRUSAK, 2001; DISTER, 2003; LEMOS, 2008)

A cultura organizacional também é um fator importante na transferência do conhecimento tácito (QUADRO 4) e é composta pela importância: i) Do ambiente favorável ao questionamento, permitindo que os diferentes pontos de vista e perspectivas sejam agrupados com o propósito de desenvolver uma nova visão (SUN; SCCOTT, 2005; LEMOS, 2008) ii) Do poder, que pode ser um fator inibidor, quando as pessoas acreditam ganharem mais enclausurando - conhecimento do que compartilhando-o na organização (HALDINHERRGARD, 2000; DAVENPORT; PRUSAK, 2003) e; iii) Do conhecimento valorizado, em que o conhecimento correto e útil é valorizado e utilizado em 
pról da organização (LEONARD; SENSIPER, 1998; HALDIN-HERRGARD, 2000).

Quadro 4: Fatores Cultura Organizacional: ambiente favorável, poder e conhecimento valorizado

\begin{tabular}{|c|c|c|}
\hline Item & Descrição & Autores \\
\hline CO1 & $\begin{array}{l}\text { A empresa conhece e valoriza minhas habilidades pessoais no meu } \\
\text { trabalho. }\end{array}$ & $\begin{array}{l}\text { Sun e Sccot (2005); Lemos } \\
(2008)\end{array}$ \\
\hline $\mathrm{CO} 2$ & $\begin{array}{l}\text { Sinto-me à vontade de sugerir e opinar com meus superiores em } \\
\text { reuniões. }\end{array}$ & $\begin{array}{l}\text { Sun e Sccot (2005); Lemos } \\
(2008)\end{array}$ \\
\hline $\mathrm{CO} 3$ & O conhecimento não é fonte de poder na empresa. & $\begin{array}{l}\text { Haldin-Herrgard }(2000) ; \\
\text { Davenport e Prusak (2003) }\end{array}$ \\
\hline $\mathrm{CO} 4$ & $\begin{array}{l}\text { Sou valorizado pelo meu conhecimento e não pelo o conhecimento } \\
\text { que compartilho. }\end{array}$ & $\begin{array}{l}\text { Haldin-Herrgard }(2000) ; \\
\text { Davenport e Prusak (2003) }\end{array}$ \\
\hline $\mathrm{CO5}$ & $\begin{array}{l}\text { A cultura da empresa favorece o questionamento ao trabalho de } \\
\text { colegas. }\end{array}$ & Leonard e Sensiper (1998). \\
\hline $\mathrm{CO} 6$ & $\begin{array}{l}\text { Sinto-me à vontade de ter opinião diferente a respeito de um } \\
\text { assunto na empresa. }\end{array}$ & Dister (2003); Lemos (2008) \\
\hline
\end{tabular}

Fonte: Adaptado de Leonard e Sensiper (1998); Haldin-Herrgard (2000); Davenport e Prusak (2003); Sun e Sccot (2005); Lemos (2008).

Para as estrategias de gestão do conhecimento (QUADRO 5) tem-se: i) - Reconhecimento e Recompensa, que incluem um sistema de reconhecimento público, a própria valorização perante o grupo, recompensas financeiras, condições sintetizadas como reciprocidade, reputação e altruísmo (DAVENPORT; PRUSAK, 1998); ii) Armazenamento do conhecimento, permitindo que o conhecimento seja armazenado em uma base de dados, acessado e utilizado por todos na organização (HANSEN; NOHRIA; TIERNEY, 1999); iii) Transmissão do Conhecimento, que ocorre pela interação entre as pessoas (MURRAY; PEIREFITTE, 2007; LEMOS, 2008); iv) Treinamento, para os individuos trocarem e combinarem conhecimentos (JOIA, 2007; LEMOS, 2008) e; iv) Rede Social Digital, que permite capturar o conhecimento tácito, conectar pessoas, acelerar e facilitar a comunicação, construir canais para catalogar ideias e sugestões; e, em outros casos, automatizar trabalhos do conhecimento (CARVALHO, 2003; MUSSI; ANGELONI, 2011). 
Marcela Augusta da Silva Gomes Silveira, Marta Araújo Tavares Ferreira, Ricardo Viana Carvalho de Paiva

Gestão de processo de compartilhamento do conhecimento tecnológico em uma empresa do setor elétrico (CEMIG)

Quadro 5: Fatores Gestão do Conhecimento: reconhecimento e recompensa, armazenamento do reconhecimento, transmissão do conhecimento, treinamento, rede social digital

\begin{tabular}{|c|c|c|}
\hline Item & Descrição & Autores \\
\hline GC1 & $\begin{array}{l}\text { A empresa encoraja e recompensa o resultado do trabalho realizado } \\
\text { em equipe. }\end{array}$ & Davenport e Prusak (2003) \\
\hline GC2 & $\begin{array}{l}\text { Sinto-me motivado a compartilhar o conhecimento que possuo com } \\
\text { outras pessoas pois a empresa valoriza e recompensa esta atitude. }\end{array}$ & Davenport e Prusak (2003) \\
\hline GC3 & $\begin{array}{l}\text { Todos na empresa são treinados nas suas atividades especificas e } \\
\text { através de provas são medidos se adquirimos o conhecimento } \\
\text { necessário. }\end{array}$ & $\begin{array}{l}\text { Hansen, Nohria, Tierney } \\
(1999)\end{array}$ \\
\hline GC4 & $\begin{array}{l}\text { A empresa incentiva minha participação em treinamentos internos e } \\
\text { externos à empresa para ampliar meus conhecimentos. }\end{array}$ & $\begin{array}{l}\text { Hansen, Nohria, Tierney } \\
\text { (1999) }\end{array}$ \\
\hline GC5 & $\begin{array}{l}\text { Os funcionários mais experientes da empresa são incentivados pela } \\
\text { a empresa a transmitir seu conhecimento aos mais novos. }\end{array}$ & $\begin{array}{l}\text { Murray e Peirefitte (2007) } \\
\text { Lemos (2008) }\end{array}$ \\
\hline GC6 & $\begin{array}{l}\text { Os funcionários mais experientes da empresa transmitem, de forma } \\
\text { espontânea, seu conhecimento aos mais novos. }\end{array}$ & $\begin{array}{l}\text { Murray e Peirefitte (2007) } \\
\text { Lemos (2008) }\end{array}$ \\
\hline GC7 & $\begin{array}{l}\text { Os empregados detêm a maior parte do conhecimento que a } \\
\text { empresa possui. }\end{array}$ & Joia (2007); Lemos (2008) \\
\hline GC8 & $\begin{array}{l}\text { Existe uma base de dados do conhecimento na empresa onde } \\
\text { encontro qualquer informação que necessito. }\end{array}$ & Joia (2007); Lemos (2008) \\
\hline GC9 & $\begin{array}{l}\text { Utilizo as redes sociais para desenvolver minhas atividades de } \\
\text { trabalho. }\end{array}$ & $\begin{array}{l}\text { Carvalho (2003); Mussi } € \\
\text { Angeloni (2011) }\end{array}$ \\
\hline GC10 & O uso das redes sociais melhora meu desempenho no trabalho & $\begin{array}{l}\text { Carvalho (2003); Carvalho } \\
(2003) ; \text { Mussi e Angelon } \\
(2011)\end{array}$ \\
\hline
\end{tabular}

Fonte: Adaptado de Hansen, Nohria, Tierney (1999); Carvalho (2003); Davenport e Prusak (2003); Joia (2007); Murray e Peirefitte (2007); Lemos (2008).

Percebe-se que o capital intelectual é a fonte de vantagem competitiva das empresas e todos os recursos em tecnologia, organização, informação, educação e skill são recursos baseados no conhecimento que diferem significativamente a partir do recurso material. $O$ valor de uma organização, então, está na capacidade dessa criar, compartilhar e reutilizar o conhecimento.

\section{METODOLOGIA}

Com o objetivo de analisar a influência dos fatores relevantes à transferência do conhecimento tecnológico em uma organização, foi elaborada uma análise da bibliografia utilizando a técnica de revisão ampla da literatura acerca do tema transferência e compartilhamento do conhecimento. A pesquisa é de natureza quantitativa, a nível descritivo quanto aos fins. Segundo Cooper e Schindler (2016) métodos quantitativos garantem a objetividade da pesquisa. 
Como estratégia de pesquisa optou-se pelo estudo de caso da CEMIG. O universo da pesquisa é composto 8.692 colaboradores, de todos os níveis hierárquicos. Para a pesquisa, obteve-se um total de 953 respondentes válidos. Salienta-se que em toda base de dados não houve nenhuma célula em branco.

A coleta dos dados se deu por meio de um questionário estruturado disponibilizado na intranet da empresa (Sharepoint), composto por 75 questões baseadas na escala likert de cinco pontos. Essa escala foi padronizada para que a escala oscilasse de -1 a 1 . Os valores positivos da escala significam que o indivíduo possui uma opinião concordante com o item, e os valores negativos que o indivíduo possui uma discordância do item. As variáveis quantitativas foram calculadas pela média e o desvio-padrão. Para apresentar e comparar os itens e os indicadores de cada constructo, a média e o intervalo percentílico bootstrap de $95 \%$ de confiança foram utilizados. O modelo de mensuração por meio de pesos e o modelo dos coeficientes foram comparados, utilizando os intervalos de confiança via bootstrap. Devido a presença de constructos de segunda ordem, também foi utilizada para tratar essa característica da estrutura de mensuração, a abordagem Two-Step. O software utilizado para as análises foi o software R (versão 3.3.0).

\section{APRESENTAÇÃO, ANÁLISE E DISCUSSÃO DOS RESULTADOS}

Essa seção estabelece a apresentação, análise e discussão dos dados resultantes da pesquisa elaborada por meio do questionário estruturado, para atender ao objetivo proposto pelo estudo de, analisar a influência dos fatores relevantes à transferência do conhecimento tecnológico em uma organização. O estudo é composto por 75 questões, sendo quatro caracterizadoras da amostra, 18 questões relacionadas a transferência do conhecimento, 24 questões relacionadas a utilização e importância de ferramentas e 29 questões relacionadas a 15 constructos- Tempo, Linguagem, Confiança, Conhecimento Valorizado, Poder, Ambiente Favorável, Rede de Relacionamento, Hierarquia, 
Mídia, Reconhecimento e Recompensa, Treinamento, Transmissão de Conhecimento, Armazenagem do Conhecimento, Redes Sociais Digitais e Compartilhamento do Conhecimento Tácito.

\subsection{Apresentação da análise descritiva da amostra}

Em busca da compreensão dos respondentes e das variáveis propostas, foi realizada a análise descritiva das variáveis caracterizadoras da amostra. Identificou-se que o "profissional Plano Técnico, Administrativo e Operacional PTAO" é a função mais frequente na pesquisa $(68,84 \%)$. A maioria dos indivíduos possuem ensino superior completo (64,64\%) e possuem entre 36 e 50 anos. Esse resultado aderece à pesquisa um grau de confiança nas respostas, devido à maturidade e boa instrução dos respondentes.

O primeiro passo da pesquisa foi analisar cada constructo sugerido no modelo. Verificou-se os fatores Idiossincráticos, quanto ao Tempo, Linguagem e Comunicação. Os resultados são mostrados na tabela 1.

Tabela 1: Média dos itens Tempo, Linguagem e Comunicação

\begin{tabular}{|c|c|c|c|}
\hline Constructo & Itens & $\begin{array}{c}\text { Médi } \\
\text { a }\end{array}$ & IC - 95\%* \\
\hline Tempo & $\begin{array}{l}\text { Eu tenho tempo e oportunidade para compartilhar com e receber } \\
\text { conhecimento de outras pessoas. }\end{array}$ & 0,17 & {$[0,13 ; 0,20]$} \\
\hline \multirow{3}{*}{ Linguagem } & $\begin{array}{l}\text { A empresa incentiva que eu tenha tempo para compartilhar o } \\
\text { conhecimento que possuo com outras pessoas. }\end{array}$ & 0,48 & {$[0,44 ; 0,51]$} \\
\hline & $\begin{array}{l}\text { Tenho facilidade de compartilhar verbalmente o conhecimento que } \\
\text { possuo. }\end{array}$ & 0,19 & {$[0,16 ; 0,23]$} \\
\hline & Conheço e entendo todas as terminologias usadas na empresa & 0,55 & {$[0,52 ; 0,58]$} \\
\hline \multirow{2}{*}{\begin{tabular}{l} 
Comunicaçã \\
\hdashline
\end{tabular}} & $\begin{array}{l}\text { Sinto-me seguro ao compartilhar informações e conhecimento com } \\
\text { meus colegas. }\end{array}$ & $-0,45$ & {$[-0,49 ;-0,41]$} \\
\hline & $\begin{array}{l}\text { Só compartilho meu conhecimento com colegas que também } \\
\text { compartilham seu conhecimento comigo. }\end{array}$ & 0,17 & {$[0,13 ; 0,20]$} \\
\hline
\end{tabular}

Fonte: Dados da pesquisa

Em relação ao Tempo, os participantes tenderam em média a concordar que possuem tempo e oportunidade para compartilhar e receber conhecimento, bem como recebem incentivos para que isso ocorra. Esse resultado é positivo para a pesquisa, haja vista que um dos principais fatores que impedem a transferência e o compartilhamento do conhecimento tácito é a falta de tempo 
(SZULANSKI, 1996). Segundo Lemos (2008) apesar do excesso de trabalho e do pouco tempo cabe, aos empregados promover as oportunidades para disponibilizar tempo para a transferência do conhecimento tácito pela organização. O que pode ser uma vantagem à empresa pesquisa.

$O$ indicador Linguagem apresenta como resultado a tendencia à concordancia para os itens. "Tenho facilidade de compartilhar verbalmente o conhecimento que possuo" e "Conheço e entendo todas as terminologias usadas na empresa". Esse resultado salienta a necessidade de que não pode haver falha para a transferência do conhecimento tácito e, por isso, faz-se necessária uma linguagem comum (SZULANSKI; 1996; HALDIN-HERRGARD, 2000; DAVENPORT; PRUSAK, 2003; DISTERER, 2003). Observa-se que os participantes entendem que não possuem dificuldade em se fazer entendidos e os empregados estão habituados com a linguagem da empresa, o que facilita a interação e o compartilhamento do conhecimento tácito. Nesse caso, a linguagem não é uma barreira à transferência do conhecimento tácito na CEMIG.

Em continuidade, a relação de confiança é um dos fatores primordiais para que haja sucesso na transferência (SZULANSKI, 1996; ROBERTS, 2000; DAVENPORT; PRUSAK, 2003 SUN; SCOTT, 2005). Para o ítem confiança os participantes tenderam em média a concordar com a questão do item "Sinto-me seguro ao compartilhar informações e conhecimento com meus colegas" e, em contrapartida, os participantes tenderam a discordar do ítem "Só compartilho meu conhecimento com colegas que também compartilham seu conhecimento comigo". O resultado demonstra que existe confiança para transferência e compartilhamento do conhecimento entre os participantes, havendo pouca restrição para a transferência de conhecimento tácito. O estudo de Lemos (2008) salienta que o nível de confiança na empresa para a troca de conhecimento é influenciado pelo bom ambiente e pelo baixo nível de disputas internas, o que facilita a interação e troca de conhecimento tácito entre os empregados. É possível que os fatores apresentados por Lemos (2008) também sejam influenciadores do resultado encontrado nessa pesquisa, na 


\section{CEMIG.}

A avaliação do fator Cultura Organizacional é apresentado na tabela 2. Esses fatores são compostos por Conhecimento valorizado, Poder e Ambiente Favorável. Em relação ao Conhecimento valorizado os participantes tenderam em média a discordar com a questão "A empresa conhece e valoriza minhas habilidades pessoais no meu trabalho" e tenderam a concordar com o item "Sinto-me à vontade de sugerir e opinar com meus superiores em reuniões". Lemos (2008), em seus estudos já salientava que contribuições baseadas em intuição feitas por indivíduos mais experientes com muitos anos de casa e reconhecidos pelo conhecimento que possuem, como consultores e analistas seniores, são mais aceitas do que sugestões de funcionários mais novos" (LEMOS, 2008, p. 90).

Tabela 2 - Média dos itens conhecimento Valorizado, Poder e Ambiente Favorável

\begin{tabular}{|c|c|c|c|}
\hline Constructo & Itens & $\begin{array}{c}\text { Médi } \\
\text { a }\end{array}$ & IC - 95\%* \\
\hline \multirow{2}{*}{$\begin{array}{l}\text { Conhecimen } \\
\text { to Valorizado }\end{array}$} & $\begin{array}{l}\text { A empresa conhece e valoriza minhas habilidades pessoais no meu } \\
\text { trabalho. }\end{array}$ & $-0,07$ & {$[-0,10 ;-0,03]$} \\
\hline & $\begin{array}{l}\text { Sinto-me à vontade de sugerir e opinar com meus superiores em } \\
\text { reuniões. }\end{array}$ & 0,33 & {$[0,29 ; 0,36]$} \\
\hline \multirow[b]{2}{*}{ Poder } & O conhecimento não é fonte de poder na empresa. & $-0,08$ & {$[-0,12 ;-0,04]$} \\
\hline & $\begin{array}{l}\text { Sou valorizado pelo meu conhecimento e não pelo o conhecimento } \\
\text { que compartilho. }\end{array}$ & $-0,03$ & {$[-0,06 ; 0,00]$} \\
\hline \multirow{2}{*}{$\begin{array}{l}\text { Ambiente } \\
\text { Favorável }\end{array}$} & $\begin{array}{l}\text { A cultura da empresa favorece o questionamento ao trabalho de } \\
\text { colegas. }\end{array}$ & $-0,08$ & {$[-0,11 ;-0,04]$} \\
\hline & $\begin{array}{l}\text { Sinto-me à vontade de ter opinião diferente a respeito de um } \\
\text { assunto na empresa. }\end{array}$ & 0,18 & {$[0,14 ; 0,21]$} \\
\hline
\end{tabular}

Fonte: Dados da pesquisa.

Observa-se que apesar dos participantes se sentirem à vontade para exporem suas opiniões com os superiores, fator esse que já havia sido relatado no item confiança, ainda existe uma percepção, de que não há valorização das habilidades pessoais no ambiente da organização. A falta de reconhecimento das habilidades pessoais pode fazer com que, em determinados momentos, a transferência do conhecimento tácito seja mitigada ou até mesmo ineficiente para a organização. Por isso, esse é um aspecto necessário de observação na empresa pesquisada, haja vista que colaboração e confiança ainda existem internamente. 
Para o indicador Poder, o resultado apresentou que os participantes tenderam em média a discordar com a questão "O conhecimento não é fonte de poder na empresa". Já no item "Sou valorizado pelo meu conhecimento e não pelo conhecimento que compartilho", apesar da média estar negativa, o intervalo bootstrap contém o zero, evidenciando que os indivíduos não tendem a concordar nem discordar desta questão. Lemos (2008) em seu estudo, apresenta que a grande maioria dos participantes considera o conhecimento tácito como fonte de poder, o que dificulta a transferência de conhecimento tácito. Fator esse encontrado também na pesquisa.

Lemos (2008) destaca que, podem haver duas visões distintas entre os empregados novos e antigos da empresa: na visão dos empregados mais novos, os empregados mais antigos se sentem ameaçados por eles e, por isso, não transferem o conhecimento que possuem. Em contrapartida, os empregados mais experientes consideram que esta cultura melhorou muito em relação ao passado, apesar de ainda existir em menor grau. Esse é um fator que deve ser melhor identificado pela CEMIG, por se tornar inibidor durante 0 processo de transferência. Colaboradores podem deixar de compartilhar conhecimento por receio de perder poder e até mesmo cargos.

Quanto ao ambiente favorável, Sun e Scott (2005) dizem que um ambiente psicologicamente seguro para expressar e experimentar diferentes opiniões e ideias é um dos fatores que facilita a disseminação de conhecimento tácito numa organização. Nesse estudo, os participantes tenderam em média a discordar que "A cultura da empresa favorece o questionamento ao trabalho de colegas", mas tendem a concordar do item "Sinto-me à vontade de ter opinião diferente a respeito de um assunto na empresa". Os participantes se sentem à vontade para terem opinião diferente a respeito de um determinado assunto na empresa. Entretanto, o ambiente da organização não favorece 0 questionamento ao trabalho de colegas. Os empregados buscam preservar os relacionamentos pessoais em detrimento da discussão que promove o compartilhamento do conhecimento tácito. Normalmente, quando há maior 
Marcela Augusta da Silva Gomes Silveira, Marta Araújo Tavares Ferreira, Ricardo Viana Carvalho de Paiva

Gestão de processo de compartilhamento do conhecimento tecnológico em uma empresa do setor elétrico (CEMIG)

liberdade e familiaridade entre as pessoas é que as críticas ocorrem de forma mais espontânea dentro de um grupo de trabalho.

O fator Estrutura Organizacional é composto por Redes de Relacionamento, Hierarquia e Mídia. A análise desses fatores é apresentada na tabela 3.

Tabela 3 - Média dos Itens Rede de Relacionamento, Hierarquia e Mídia

\begin{tabular}{c|l|c|c}
\hline Constructo & Itens & Média & IC - 95\%* \\
\hline $\begin{array}{c}\text { Rede de } \\
\text { Relacionamento }\end{array}$ & $\begin{array}{l}\text { Eu sei exatamente quem na empresa possui o conhecimento } \\
\text { específico que pode ajudar o meu trabalho. }\end{array}$ & 0,21 & {$[0,17 ; 0,24]$} \\
\cline { 2 - 4 } & $\begin{array}{l}\text { Desconheço quem detém o conhecimento mais profundo de } \\
\text { determinado assunto dentro da empresa. }\end{array}$ & $-0,07$ & {$[-0,11 ;-0,04]$} \\
\cline { 2 - 4 } Hierarquia & $\begin{array}{l}\text { Tenho acesso às pessoas que detém o conhecimento tácito que } \\
\text { necessito, independente do nível hierárquico em que se } \\
\text { encontra. }\end{array}$ & 0,18 & {$[0,14 ; 0,21]$} \\
\hline & $\begin{array}{l}\text { Sinto-me à vontade de pedir ajuda quando a posição de quem } \\
\text { detém o conhecimento é superior a minha }\end{array}$ & 0,40 & {$[0,37 ; 0,43]$} \\
\hline \multirow{2}{*}{ Mídia } & $\begin{array}{l}\text { A mídia que mais utilizo para interagir com pessoas na empresa } \\
\text { cujo conhecimento é importante para meu trabalho é a conversa } \\
\text { pessoal. }\end{array}$ & 0,14 & {$[0,10 ; 0,18]$} \\
\hline & $\begin{array}{l}\text { A mídia que mais utilizo para interagir com pessoas na empresa, } \\
\text { cujo conhecimento é importante para o meu trabalho é através } \\
\text { de e-mail, telefone, memorandos, relatórios e afins. }\end{array}$ & 0,40 & {$[0,37 ; 0,43]$} \\
\hline
\end{tabular}
Fonte: Dados da pesquisa.

Para Rede de Relacionamento os participantes tenderam, em média, a concordar com o item "Eu sei exatamente quem na empresa possui o conhecimento específico que pode ajudar o meu trabalho" e, em contrapartida tenderam a discordar do item "Desconheço quem detém o conhecimento mais profundo de determinado assunto dentro da empresa". Identificar tanto a necessidade que se tem de determinado conhecimento quanto o conhecimento para atender a esta necessidade é uma das dificuldades para a efetiva transferência de conhecimento tácito (SZULANSKI, 1996; O'DELL; GRAYSON, 1998; DAVENPORT; PRUSAK, 2003). Apesar de a empresa em estudo ser de grande porte, observa-se que os participantes sabem quem detém e onde buscar o conhecimento específico para ajudar no trabalho. Aspecto esse que também foi ressaltado no item confiança e conhecimento valorizado.

Para Hierarquia os respondentes tenderam em média, a concordar com todos os itens: "Tenho acesso às pessoas que detém o conhecimento tácito 
que necessito, independentemente do nível hierárquico em que se encontra" e "Sinto-me à vontade de pedir ajuda quando a posição de quem detém o conhecimento é superior a minha". Percebe-se que mesmo quando a pessoa não tem acesso a quem detém o conhecimento, os participantes se sentem à vontade em pedir ajuda aos demais, sejam superiores ou não. $O$ resultado desse item é importante para a organização em estudo, haja vista que as pessoas não são inacessíveis em virtude do nível hierárquico que ocupam. É necessário que as pessoas estejam acessíveis quando se necessita de seu conhecimento, independentemente de sua posição hierárquica na organização, para que a transferência do conhecimento tácito ocorra (SZULANSKI, 1996; FAHEY; PRUSAK, 2001; DISTERER, 2003).

Em relação a mídia os participantes tenderam em média a concordar com as questões "A mídia que mais utilizo para interagir com pessoas na empresa cujo conhecimento é importante para meu trabalho é a conversa pessoal" e "A mídia que mais utilizo para interagir com pessoas na empresa, cujo conhecimento é importante para o meu trabalho é através de e-mail, telefone, memorandos, relatórios e afins". Apesar de os participantes reconhecem a importância da interação pessoal, conforme já havia sido indicado e salientado por Leonard e Sensiper (1998), Stwart (1998) e Roberts (2000), ainda se utiliza e-mail, telefone, memorandos e afins para ocorrência das interações. Resultado contraditório quando se observa que na empresa em questão se tem tempo para interações, para aprendizados e reconhece-se a importância da face a face, mas os meios formais ainda são mais utilizados.

O fator Estratégia de Transferência do Conhecimento, apresenta os itens Reconhecimento e recompensa, Treinamento, Transmissão de Conhecimento, Armazenagem do Conhecimento e Redes Sociais na tabela 4. 
Marcela Augusta da Silva Gomes Silveira, Marta Araújo Tavares Ferreira, Ricardo Viana Carvalho de Paiva

Gestão de processo de compartilhamento do conhecimento tecnológico em uma empresa do setor elétrico (CEMIG)

Tabela 4 - Média dos Itens Reconhecimento e Recompensa, Treinamento, Transmissão do Conhecimento, Armazenamento do Conhecimento e Redes Sociais Digitais

\begin{tabular}{|c|c|c|c|}
\hline Constructo & Itens & $\begin{array}{c}\text { Médi } \\
\text { a }\end{array}$ & IC - 95\%* \\
\hline \multirow{2}{*}{$\begin{array}{c}\text { Reconheciment } \\
\text { o e } \\
\text { Recompensa }\end{array}$} & $\begin{array}{l}\text { A empresa encoraja e recompensa o resultado do trabalho } \\
\text { realizado em equipe. }\end{array}$ & $-0,14$ & {$[-0,18 ;-0,10]$} \\
\hline & $\begin{array}{l}\text { Sinto-me motivado a compartilhar o conhecimento que possuo } \\
\text { com outras pessoas pois a empresa valoriza e recompensa esta } \\
\text { atitude. }\end{array}$ & $-0,15$ & {$[-0,19 ;-0,12]$} \\
\hline \multirow[t]{2}{*}{ Treinamento } & $\begin{array}{l}\text { Todos na empresa são treinados nas suas atividades especificas } \\
\text { e através de provas são medidos se adquirimos o conhecimento } \\
\text { necessário. }\end{array}$ & $-0,28$ & {$[-0,32 ;-0,25]$} \\
\hline & $\begin{array}{l}\text { A empresa incentiva minha participação em treinamentos internos } \\
\text { e externos à empresa para ampliar meus conhecimentos. }\end{array}$ & $-0,12$ & {$[-0,16 ;-0,08]$} \\
\hline \multirow{2}{*}{$\begin{array}{l}\text { Transmissão de } \\
\text { Conhecimento }\end{array}$} & $\begin{array}{l}\text { Os funcionários mais experientes da empresa são incentivados } \\
\text { pela a empresa a transmitir seu conhecimento aos mais novos. }\end{array}$ & $-0,22$ & {$[-0,26 ;-0,18]$} \\
\hline & $\begin{array}{l}\text { Os funcionários mais experientes da empresa transmitem, de } \\
\text { forma espontânea, seu conhecimento aos mais novos. }\end{array}$ & 0,05 & {$[0,02 ; 0,09]$} \\
\hline \multirow{2}{*}{$\begin{array}{c}\text { Armazenagem } \\
\text { do } \\
\text { Conhecimento }\end{array}$} & $\begin{array}{l}\text { Os empregados detêm a maior parte do conhecimento que a } \\
\text { empresa possui. }\end{array}$ & 0,53 & {$[0,50 ; 0,56]$} \\
\hline & $\begin{array}{l}\text { Existe uma base de dados do conhecimento na empresa onde } \\
\text { encontro qualquer informação que necessito. }\end{array}$ & $-0,24$ & {$[-0,28 ;-0,21]$} \\
\hline \multirow{2}{*}{$\begin{array}{l}\text { Redes Sociais } \\
\text { Digitais }\end{array}$} & $\begin{array}{l}\text { Utilizo as redes sociais para desenvolver minhas atividades de } \\
\text { trabalho. }\end{array}$ & $-0,34$ & {$[-0,38 ;-0,30]$} \\
\hline & O uso das redes sociais melhora meu desempenho no trabalho & $-0,17$ & {$[-0,21 ;-0,13]$} \\
\hline
\end{tabular}

Fonte: Dados da pesquisa.

No indicador Reconhecimento e Recompensa os participantes tenderam em média a discordar com as questões "A empresa encoraja e recompensa o resultado do trabalho realizado em equipe" e "Sinto-me motivado a compartilhar o conhecimento que possuo com outras pessoas pois a empresa valoriza e recompensa esta atitude". O resultado dessa pesquisa contraria as ideias de Szulanski (1996). Para o autor, as pessoas precisam ser adequadamente reconhecidas e recompensadas para que sejam motivadas a compartilhar 0 conhecimento que possuem. O resultado apresenta que na organização estudada entende-se que o reconhecimento dos profissionais pela sua contribuição para a empresa é suficiente para incentivar o compartilhamento de conhecimento. Porém, o resultado foi similar aos encontrados no estudo de Lemos (2008). O sistema de reconhecimento e recompensa das empresas estudadas privilegia o trabalho individual em detrimento do trabalho em grupo, o que é um fator restritivo à transferência de conhecimento tácito e precisa ser aprimorado na empresa pesquisada. 
Com o indicador Treinamento, os respondentes também tenderam a discordar das questões "Todos na empresa são treinados nas suas atividades específicas e através de provas são medidos se adquirimos o conhecimento necessário" e "A empresa incentiva minha participação em treinamentos internos e externos à empresa para ampliar meus conhecimentos". Durante a pesquisa, observou-se que a empresa estudada reduziu consideravelmente 0 investimento em treinamento interno e externo e, no momento, não se vislumbra a utilização de práticas mais individualizadas de treinamento. A falta de perspectiva e de treinamento pode ser um fator inibidor. Autores como Joia (2007) e Fleury e Oliveira Junior (2001) salientam que o treinamento é uma atividade estratégica e que conduzem a um aumento das habilidades e da motivação dos empregados. Dessa forma, a própria organização pode estar dificultando a transferência de conhecimento de alta especificidade.

Já no resultado do item Armazenagem do Conhecimento, os participantes tenderam, em média, a concordar com a questão "Os empregados detêm a maior parte do conhecimento que a empresa possui" e a discordarem com "Existe uma base de dados do conhecimento na empresa onde encontro qualquer informação que necessito" Esse resultado reflete as pesquisas de Nonaka e Takeuchi (1997), Hansen, Nohria e Tierney (1999) e Joia (2007). O investimento em tecnologia da informação não é apropriado para a estratégia de personalização, pois o conhecimento tácito não é passível de codificação. Nesta estratégia, a empresa acredita na experiência acumulada por seus funcionários, pois o conhecimento está relacionado diretamente à pessoa que 0 desenvolveu. Observa-se que 0 empregado detém 0 conhecimento tácito e não há registros físicos sobre esses conhecimentos. A maioria dos participantes afirma que o conhecimento da empresa está nas pessoas e que o conhecimento mais relevante não é passível de formalização.

Em continuidade, na avaliação das Redes Sociais Digitais, que foi proposto e inserido no modelo, os participantes tenderam a discordar dos itens "Utilizo as redes sociais para desenvolver minhas atividades de trabalho" e "O uso das redes sociais melhora meu desempenho no trabalho". Conexão entre 
os indivíduos que constituem as redes sociais digitais passam a existir quando indivíduos se utilizam dos recursos tecnológicos para a sua interação (NEVES, 2007). As organizações podem se beneficiar das redes sociais digitais e das mídias sociais pela sua presença em diferentes áreas (MUSSI; ANGELONI, 2011). Do ponto de vista intraorganizacional, a adoção de mídias sociais pode auxiliar na comunicação interna, bem como na construção de uma cultura compartilhada (ANGELONI, 2008). Nessa perspectiva, o resultado desse item reflete que, na CEMIG, a relação uso x importância das redes sociais digitais no compartilhamento ou transferência do conhecimento está abaixo do esperado considerando que a empresa é uma empresa de base tecnológica.

O resultado para o indicador Compartilhamento do Conhecimento Tácito também teve como média a concordância dos itens "Eu compartilho o conhecimento tácito que possuo com meus colegas" e "Meus colegas compartilham comigo o conhecimento tácito que possuem". Percebe-se similaridade dos resultados obtidos nessa pesquisa em relação ao estudo de Lemos (2008). O autor identificou que, na empresa estudada "os participantes transferem o conhecimento tácito que possuem. Entretanto, a percepção é um pouco diferente quando se trata de adquirir o conhecimento tácito. Os participantes afirmam que algumas pessoas relutam em transferir 0 conhecimento tácito que detém" (LEMOS, 2008, p. 109). Assim, observa-se que o compartilhamento do conhecimento tácito entre os indivíduos não é um processo natural e frequente, como esperado para uma empresa de grande porte, de base tecnológica e que tem investido constantemente em recursos para a gestão do conhecimento.

\subsection{A influência dos fatores relevantes à transferência do conhecimento tecnológico}

Para verificar a qualidade do ajuste dos modelos e seus constructos, foram utilizados o $R^{2}$ e o GoF. O $R^{2}$ representa, em uma escala de 0 a 100 , o quanto os constructos independentes explicam os dependentes, sendo que 
quanto mais próximo de $100 \%$ melhor. Já o GoF é uma média geométrica da média das AVEs dos constructos com a média dos $\mathrm{R}^{2}$ do modelo. Ele varia de $0 \%$ a $100 \%$, não havendo ainda valores de corte para considerar um ajuste como bom ou ruim, mas sabe-se que quanto mais próximo de $100 \%$ melhor o ajuste (HAIR, et al., 2009).

A tabela 5 apresenta os resultados encontrados na pesquisa quanto a influencia dos fatores de transferência do conhecimento tácito: Idiossincráticos, Cultura e Estrutura Organizacional e Estratégia de Transferência do Conhecimento.

Tabela 5 - Modelo Estrutural

\begin{tabular}{|c|c|c|c|c|c|c|}
\hline Constructo & Itens & $\beta$ & $\begin{array}{l}\text { E.P. } \\
(\beta)^{1}\end{array}$ & $\begin{array}{l}\text { I.C. - } \\
95 \%^{2} \\
\end{array}$ & Valor-p & $\mathbf{R}^{2}$ \\
\hline \multirow{4}{*}{$\begin{array}{l}\text { Transferência } \\
\text { do } \\
\text { Conheciment } \\
\text { o Tácito }\end{array}$} & Fatores Idiossincráticos & $\begin{array}{l}0,2 \\
7\end{array}$ & $\begin{array}{c}0,0 \\
3\end{array}$ & $\begin{array}{c}{[0,20} \\
; \\
0,35]\end{array}$ & 0,000 & \multirow{4}{*}{$31,80 \%$} \\
\hline & Cultura Organizacional & $\begin{array}{l}0,0 \\
5\end{array}$ & $\begin{array}{c}0,0 \\
4\end{array}$ & $\begin{array}{c}{[-} \\
0,04 \\
0,15]\end{array}$ & 0,280 & \\
\hline & Estrutura Organizacional & $\begin{array}{l}0,1 \\
7\end{array}$ & $\begin{array}{l}0,0 \\
3\end{array}$ & $\begin{array}{c}{[0,09} \\
; \\
0,24]\end{array}$ & 0,000 & \\
\hline & $\begin{array}{l}\text { Estratégia de Transferência do } \\
\text { Conhecimento }\end{array}$ & $\begin{array}{c}0,2 \\
2\end{array}$ & $\begin{array}{l}0,0 \\
4\end{array}$ & $\begin{array}{c}{[0,15} \\
; \\
0,30] \\
\end{array}$ & 0,000 & \\
\hline
\end{tabular}

Fonte: Dados da pesquisa.

Ao se analisar os constructos em relação à Transferência do Conhecimento Tácito, Identificou-se que, quanto maior forem os Fatores Idiossincráticos, da Estrutura Organizacional e da Estratégia de Gestão do Conhecimento maior será a Transferência de Conhecimento Tácito. Isso porque há uma relação positiva (valor- $\mathrm{p}=0,000$ ) e significativa (Fatores Idiossincráticosdos $\beta=0,27[0,20 ; 0,35]$; Estrutura Organizacional $\beta=0,17[0,09$; $0,24]$; Estratégia de Gestão do Conhecimento $\beta=0,22[0,15 ; 0,30]$ ) dos fatores propostos. Em contrapartida, não houve influência significativa da Cultura Organizacional sobre a Transferência de Conhecimento Tácito. Resultados que podem ser observados na Figura 1. 
Figura 1 - Modelo Estrutural Proposto

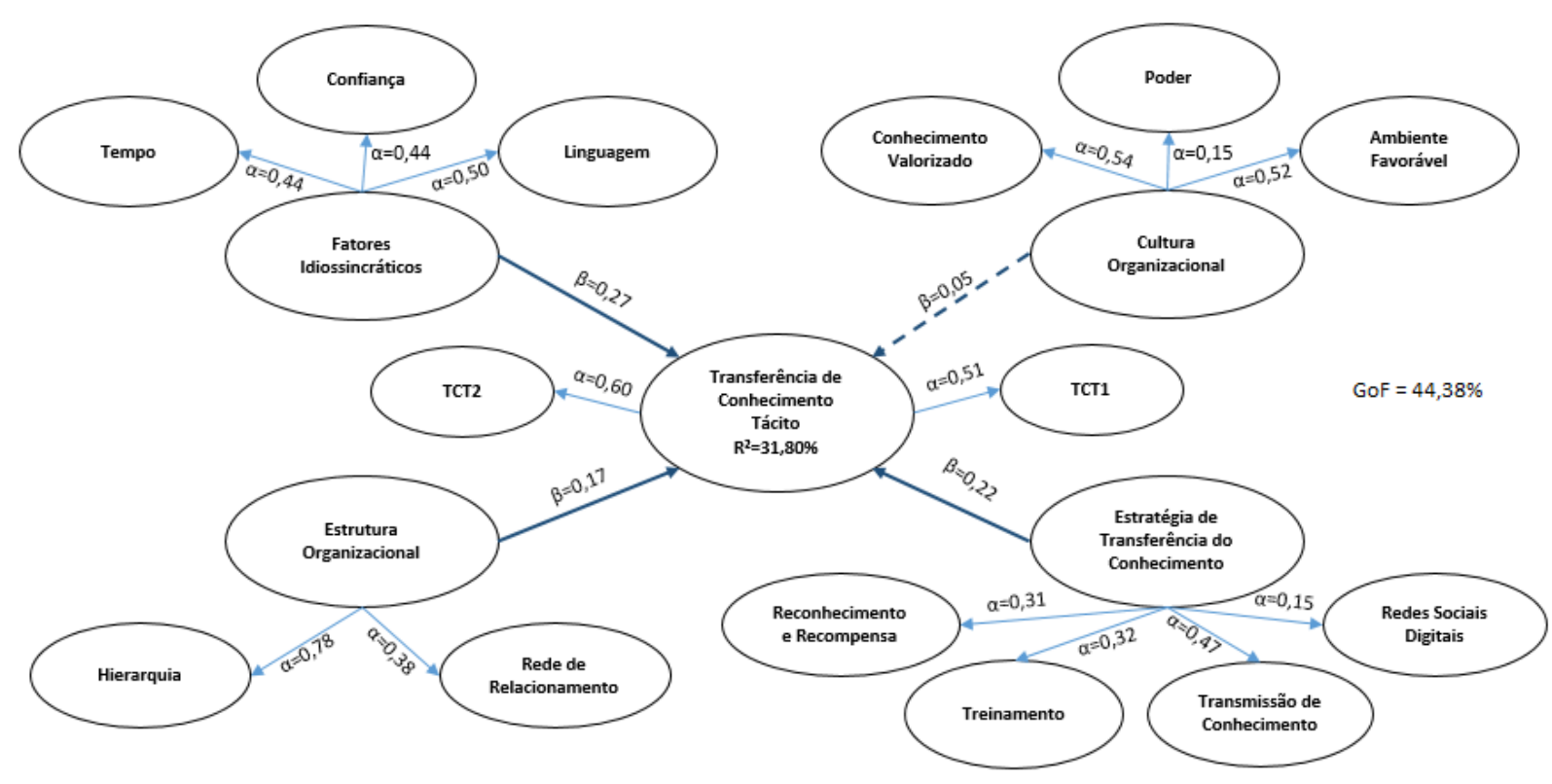

Fonte: Dados da pesquisa.

O resultado dessa pesquisa confirma que o conhecimento tácito e seu compartilhamento depende diretamente dos processos estruturais da organização, bem como do próprio indivíduo detentor do conhecimento. Fatores esses salientados por Szulanski (1996), Nonaka e Takeuchi, 1997 e Grant (2007) em seus estudos. Portanto, considera-se que o fator idiossincrático é determinante para o compartilhamento do conhecimento tácito, haja vista que sem confiança, tempo, talento e habilidades de linguagem a transferência do conhecimento pode não ser eficaz.

Porém, chama-se a atenção para o aspecto cultural. Faz-se necessário eliminar as barreiras à livre circulação do conhecimento e informação nas organizações, criando condições certas, infraestruturas organizacionais e técnicas, gerenciamento dos funcionários e da cultura da empresa, o que não foi identificado como fator influenciador na pesquisa. Cabe a organização estimular mecanismos e ações que facilitem a interação e comunicação dentro da empresa e a utilização dos sistemas que assegurem a efetiva comunicação e integração de esforços (DAFT; LENGEL, 1986). 
Os Fator Idiossincráticos, Cultura Organizacional, Estrutura Organizacional e Estratégias de Transferência do Conhecimento, forma capazes de explicar 31, 80\% da Transferência do Conhecimento Tácito. Sendo os Fator Idiossincráticos $(0,27)$ e as Estratégias de Transferência do Conhecimento $(0,22)$, maiores influenciadores da Transferência desse conhecimento. Nessa perspectiva, salienta-se os dizeres de Hansen, Nohria e Tierney, 1999 e Joia, 2007, em que o conhecimento tácito, por ser obtido por de processos pessoais, mas não pode ser gerenciado de forma similar ao conhecimento explícito, que é facilmente estruturado. Por isso, os Fatores Idiossincráticos, Cultura e Estrutura Organizacional e Estratégias de Transferências do Conhecimento são influenciadores no processo de Transferência do Conhecimento Tácito na organização.

\section{CONSIDERAÇÕES FINAIS}

Esse estudo buscou analisar a influência dos fatores relevantes à transferência do conhecimento tecnológico na CEMIG. Reconhece-se, por meio dos levantamentos teórico realizados, que a transferência do conhecimento tácito é um fator relevante para as organizações por ser fonte de vantagem competitiva organizacional. Pelo estudo identificou-se que a CEMIG não possui uma política ou estratégia definida para incentivar a transferência do conhecimento tácito e o estudo não mostrou nenhuma restrição com relação aos fatores idiossincráticos. Percebeu-se que entre os empregados a linguagem flui espontaneamente e há uma boa relação de confiança. Pode-se constatar também que o tempo não é um fator inibidor. Porém, observou-se que a cultura organizacional da empresa ainda é um aspecto a ser tratado em relação ao compartilhamento do conhecimento tácito.

A organização não valoriza o conhecimento baseado na experiência pessoal, mesmo que esse ainda seja visto como fonte de poder pelos empregados. Acredita-se que as mudanças ocorridas nos últimos quinze anos de caráter regulatório, estratégico e organizacional, a rápida redução do quadro 
próprio e o longo período sem contratar novos empregados tenha agravado essa situação. Essa pesquisa contribui para o aprofundamento dos estudos sobre transferência e compartilhamento do conhecimento com 0 desenvolvimento de um modelo teórico que buscou explicar as relações existentes entre os constructos e a estratégia de gestão do conhecimento adotada na empresa.

Por tratar-se de um estudo de caso único e holístico, baseado nas percepções dos próprios participantes sobre a transferência e compartilhamento do conhecimento tácito na CEMIG, seu resultado não pode ser generalizado para além do caso analisado. Em virtude da particularidade do caso estudado, o modelo proposto pode ser objeto de novas pesquisas, de maneira a enriquecer $\mathrm{o}$ conhecimento teórico sobre a transferência e compartilhamento do conhecimento tácito e, se o modelo proposto se aplica a outra organização.

\section{REFERÊNCIAS}

ANGELONI, M. T. Organizações do Conhecimento: infraestrutura, pessoas e tecnologias. São Paulo: Saraiva, 2008.

CAMPOS, M. Z. C. R. Disseminação e transferência do conhecimento tecnológico gerado em projetos de pesquisa e desenvolvimento: estudo de caso em empresa do setor elétrico brasileiro. 2008. 102 f. Dissertação (Mestrado em Administração) - Pontifícia Universidade Católica de Minas Gerais, Belo Horizonte, 2008.

CARVALHO, R. B. Tecnologia da informação aplicada à gestão do conhecimento. Belo Horizonte: C/Arte, 2003.

COOPER, D. R.; SCHINDLER, P. S. Métodos de Pesquisa em Administração. 12. ed. Rio de Janeiro: Editora Bookman. 2016.

DAVENPORT, T. H.; PRUSAK, L. Conhecimento Empresarial: Como as organizações gerenciam seu capital. 12. ed. Rio de Janeiro: Elsevier, 2003.

DAFT, R. L.; LENGEL, R. H. Organizational information requirements, media richness and structural design. Management Science, v. 32, n. 5, p. 554-571, 1986. 
DAFT, R. L.; LENGEL, R. H; TREVINO, L. K. Message Equivocality, Media Selection and Manager Performance: implications for information systems. MIS Quarterly, p. 355-366, set. 1987.

DISTERER, G. Fostering Knowledge Sharing: Why and How? In: REIS, A., ISAIAS, P. (Org.). Proceedings of the IADIS International Conference eSociety 2003, Lisbon, p. 219-226, 2003.

DRUCKER, P. F. Concept of the Corporation. New Brunswick, N.J., U.S.A: Transaction Publishers, 1993.

. O melhor de Peter Drucker: o homem, a administração e a sociedade. São Paulo: Nobel, 2013.

FAHEY, L.; PRUSAK, L. The eleven deadliest sins of knowledge management. California Management Review, v. 40, n. 3, p. 265-76, 1998.

FLEURY, M. T. L.; OLIVEIRA JUNIOR, M. M. Gestão estratégica do Conhecimento: integrando aprendizagem, conhecimento e competências. São Paulo: Atlas, 2001.

HALDIN-HERRGARD, T. Difficulties in Diffusion of Tacit Knowledge in Organizations. Journal of Intellectual Capital, v. 1, n. 4, p. 357-365, 2000.

HANSEN, M.; NOHRIA, N.; TIERNEY, T. What's your Strategy for Managing Knowledge? Harvard Business Review, p.1-10, mar./abr. 1999.

HAIR, J. F. et al. Análise Multivariada de Dados. Porto Alegre: Bookman, 2009.

JOIA, L. A. Knowledge Management Strategies: Creating and Testing a Measurement Scale. International Journal of Learning and Intellectual Capital. Inderscience, v. 4, n. 3, p. 203-221, 2007.

LEMOS, B. N. Fatores relevantes de sucesso à transferência do conhecimento tácito: evidências empírico-exploratórias em uma empresa petrolífera brasileira. 2008. 128 f. Dissertação (Mestrado Executivo em Gestão Empresarial) - Fundação Getúlio Vargas, Escola Brasileira de Administração Pública e de Empresas, Rio de Janeiro, 2008.

LEONARD, B. D.; SENSIPER, S. The Role of Tacit Knowledge in Group Innovation. California Management Review, v. 40, n. 3, p. 112-132, 1998.

MORAES, M. C. O Paradigma Educacional Emergente. 16. ed. Rio de Janeiro: Editora Papipus, 2014. 
MURRAY, S. R.; PEYREFITTE, J. Knowledge Type and Communication Media Choice in the Knowledge Transfer Process. Journal of Managerial Issues, $v$. 19, n. 1, p. 111-133, 2007.

MUSSI, C. C.; ANGELONI, M. T. Meios de compartilhamento do conhecimento no contexto de projetos de tecnologia da informação. Revista Eletrônica de Estratégia \& Negócios, v. 4, p. 30-60, 2011.

NEVES, A. Web 2.0: Definição, Características e Exemplos. 2007. Disponível em: <http://kmol.online.pt/artigos/2007/07/01/web-20-definicao-caracteristicase-exemplos>. Acesso em: 07 nov. 2014.

NONAKA, I. The knowledge-creating company. Harvard Business Review, v. 69, n. 6, p. 96-104, nov./dez. 1991.

NONAKA, I.; TAKEUCHI, H. Criação de conhecimento na empresa. Rio de Janeiro: Campus, 1997.

O'DELL, C.; GRAYSON, C. J. If Only We Knew What We Know: Identification and Transfer of Internal Best Practices. California Management Review, v. 40, n. 3, p. 154-174, 1998.

ROBERTS, J. From Know-How to Show-How? Questioning the Role of Information and Communication Technologies in Knowledge Transfer.

Technology Analysis and Strategic Management, v. 12, n. 4, p. 429-443. 2000.

RUTTEN, W., BLAAS-FRANKEN, J.; MARTIN H. The impact of (low) trust on knowledge sharing. Journal of knowledge Management, v. 20, n. 2, p. 199214, 2016.

SIMONE, C.; ACKERMAN, M.; WULF, V. Knowledge management in practice: A special issue. Computer Supported Cooperative Work: CSCW: An International Journal, v. 21, n. 2-3, p.109-110, jun. 2012.

SUN, P.; SCOTT, J. An investigation of barriers to knowledge transfer. Journal of Knowledge Management, v. 9, n. 2, p. 75-90, 2005.

SZULANSKI, G. Exploring internal stickiness: impediments to the transfer of best practice within the firm. Strategic Management Journal, v. 17, $n$. especial, p. 27-43, 1996.

URSO, G. et al. Knowledge Sharing is Power. Transition Studies Review, v. 16, p. 352-367, jun. 2009. 


\title{
MANAGEMENT OF THE PROCESS OF SHARING TECHNOLOGICAL KNOWLEDGE IN NA ELETRIC SECTOR COMPANY (CEMIG)
}

\begin{abstract}
Introduction: The transfer of tacit knowledge is a competitive advantage factor for organizations. In this context, this study aims to analyze the influence of relevant factors on the transfer of technological knowledge in an organization. Objective: It sought to understand the theories and concepts applied to knowledge, knowledge management and the transfer and sharing of knowledge. Methodology: To achieve this goal, a structured questionnaire was applied, with likert scale of 5 points. This research is a descriptive, quantitative research that has the object of analysis the Energy Company of Minas Gerais- CEMIG. Results: As a result, it has been identified that the company does not have a defined policy or strategy to encourage the transfer of knowledge and still needs to improve the organizational culture that encourages its transmission. Although there are no restrictions on idiosyncratic factors and organizational structure. Conclusions: It is concluded that Time, Language, Confidence, Valued Knowledge, Power, Favorable Environment, Relationship Network, Hierarchy, Media, Recognition and Reward, Training, Knowledge Transmission, Knowledge Storage, Digital Social Networks are direct influencers of Tacit Knowledge Sharing.
\end{abstract}

Descriptors: Knowledge. Knowledge management. Transfer of knowledge. Sharing of knowledge. Electrical sector.

\section{GESTIÓN DE PROCESOS DE TRANSFERENCIA DE CONOCIMIENTO TECNOLÓGICO EN UNA EMPRESA DEL SECTOR ELECTRICO (CEMIG)}

\begin{abstract}
RESUMEN
Introducción: La transferencia del conocimiento tácito es un factor de ventaja competitiva para las organizaciones. En este sentido, este estudio tiene como objetivo analizar la influencia de los factores importantes de la transmisión del conocimiento tecnológico en una organización. Objetivo: Se indagó la comprensión de las teorías y los conceptos aplicados al conocimiento; a la gestión, transferencia y a la forma de compartir el conocimiento. Metodología: Para alcanzar este objetivo, se aplicó un cuestionario estructurado con la escala liker de 5 puntos. Esta investigación es descriptiva y cualitativa que tiene como objeto de análisis la Compañía Energética de Minas Gerais - CEMIG. Resultados: El estudio obtuvo resultados que demostraban que la empresa no posee una política o estrategia definida para incentivar la transferencia del conocimiento y además necesita mejorar la cultura organizacional existente para que incentive dicha transmisión. A pesar que no existen restricciones en cuanto a los factores idiosincráticos y estructura organizacional. Conclusiones: Se concluyó que los factores Tiempo, Lenguaje, Confianza, Valorización del Conocimiento, Poder, Ambiente Favorable, Redes de Relacionamiento, Jerarquía, Medios de Comunicación, Reconocimiento y Recompensa, Entrenamiento, Transmisión y Almacenamiento del Conocimiento, Redes Sociales Digitales influyen
\end{abstract}

Inf. Inf., Londrina, v. 23, n. 2, p. 538 - 565, maio/ago. 2018

http://www.uel.br/revistas/informacao/ 
Marcela Augusta da Silva Gomes Silveira, Marta Araújo Tavares Ferreira, Ricardo Viana Carvalho de Paiva

Gestão de processo de compartilhamento do conhecimento tecnológico em uma empresa do setor elétrico (CEMIG)

directamente en la transferencia del Conocimiento Tácito.

Descriptores: Conocimiento. Gestión del conocimiento. Transferencia del conocimiento. Compartir conocimiento. Sector eléctrico.

Recebido: 10.03. 2017

Aceito: 27.02 .2018

Inf. Inf., Londrina, v. 23, n. 2, p. $538-565$, maio/ago. 2018

http://www.uel.br/revistas/informacao/ 